\title{
THE IMPACT OF LIHTC PROGRAM ON LOCAL SCHOOLS
}

\author{
WENHUA DI \\ AND JAMES C. MURDOCH \\ RESEARCH DEPARTMENT \\ WORKING PAPER 1006
}

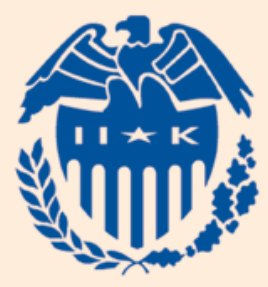

Federal Reserve Bank of Dallas 


\title{
The Impact of LIHTC Program on Local Schools
}

\author{
Wenhua Di \\ Senior Economist, Community Affairs \\ Federal Reserve Bank of Dallas \\ Email: wenhua.di@dal.frb.org \\ Phone: (214) 922-5534 \\ James C. Murdoch \\ Professor of Economics and Public Policy \\ University of Texas at Dallas \\ E-Mail: murdoch@utdallas.edu \\ Phone: (972) 883-4989
}

\begin{abstract}
The low-income housing tax credit (LIHTC) program has developed over two million rental homes for low-income households since 1986. The perception of deterioration in school quality has been a main reason for community opposition to LIHTC projects in middle-and upper-income areas. In this paper, we examine the impact of LIHTC projects on the nearby school performance. The LIHTC projects tend to have positive and statistically significant impacts on school performance the year they are placed in service and this finding is robust to various specifications. Offsetting these, the one year lag effects are negative and of similar or smaller magnitude.
\end{abstract}

\section{Disclaimer}

The views expressed in the paper are those of the authors and do not necessarily represent the views of the Federal Reserve Bank of Dallas or the Federal Reserve System. 


\section{Introduction}

In high-cost metropolitan areas, it is challenging for low-income working families to find housing in decent neighborhoods. Many end up in poor housing conditions, which are detrimental not only to the occupants, but also to their neighbors and neighborhoods. In response, several public policy instruments have been implemented, including housing choice vouchers, inclusionary zoning, tax breaks for low-income housing developments and local affordable housing mandates or offsets. The low-income housing tax credit (LIHTC) program, our interest, provides incentives to develop quality multifamily rental units that are available at below market rate rents for low-income households.

Previous studies of the LIHTC program have suggested that LIHTC projects and school performance both affect nearby property values, but very few have considered any direct relationships between subsidized units and school outcomes. In general, LIHTC housing developments are not likely to cause significant declines in neighboring property values and may even have positive impacts (Ingrid Ellen et al. 2005; Roxanne Ezzet-Lofstrom and James Murdoch 2007). Negative impacts exist for some projects under certain circumstances, but they tend to be small and can be reduced if the units are well designed and managed, compatible with the host neighborhood and not concentrated among other subsidized housing (Mai Nguyen 2005). Several studies have considered school-level variables and property values. A recent study of the Philadelphia residential housing market (TRF 2009) found that elementary schools' test scores significantly influence home sales prices. Kathy Hayes and Lori Taylor (1996) found a similar result, based on the school performance, in the Dallas area. Eric Brunner, James Murdoch and Mark Thayer (2002) looked at school finances, finding that equalization of funding in California not only reduced school performance but also the property value premiums 
previously associated with school quality. John Clapp, Anupam Nanda and Stephen Ross (2008) found that the increases in the percent Hispanic in local schools have an even more negative effect than decreases in test scores on housing prices in Connecticut.

How LIHTC developments affect neighborhoods and schools depends on the local conditions and the type of development. Lan Deng (2009) looked at eight socioeconomic indicators of neighborhoods hosting LIHTC projects. ${ }^{1}$ She found that most of the LIHTC neighborhoods experienced positive changes when compared to the comparison neighborhoods. Specifically, LIHTC properties invested in high-poverty neighborhoods are the most likely to generate positive impacts, while LIHTC invested in middle-class neighborhoods are the least likely to do so. The effects are more mixed in "working-class" neighborhoods. The role of LIHTC units may depend on whether the LIHTC project generates new or rehabilitated units. If LIHTC projects rehabilitate existing housing, they are likely to improve the existing neighborhood conditions by removing some of the blight in deteriorating areas (Anna Santiago, George Galster, and Peter Tatian 2001) in addition to improving the living conditions of the project occupants. ${ }^{2}$ However, rehabilitated properties are more likely to be in neighborhoods that remain isolated with limited education and job opportunities. In Texas, the majority of LIHTC

\footnotetext{
${ }^{1}$ The eight indicators include: 1) unemployment rate, 2) poverty rate, 3) percentage of households receiving public assistance, 4) median household income as a percentage of metropolitan median household income, 5) median gross rent as a percentage of metropolitan median gross rent, 6) median housing value as a percentage of metropolitan median housing value, 7) number of units built in the last 10 years, and 8) single-family mortgage approval rate. ${ }^{2}$ Rehabilitation project sometimes generate units because the properties may be underutilized or unlivable before rehabilitation.
} 
projects produce new units. If new units are located in segregated low-income neighborhoods, even though rents are subsidized, tenants may still suffer from the social problems associated with concentrated poverty. If the new units are built in higher income neighborhoods, existing home owners may exhibit a "not in my backyard" (NIMBY) attitude, due to their perceptions about the designs and quality of the multifamily properties, potential changes in neighborhood demographics, decline in open space, decreases in public services and safety and impacts on property values (Anthony Downs 1992; Meryl Finkel et al. 1996; Rolf Pendall 1999; Margery Turner, Susan Popkin, and Mary Cunningham 2000; Nguyen 2005). Moreover, the parents in the receiving neighborhoods may be concerned that their local public schools will become overcrowded and that low-income kids from the LIHTC units will exert negative peer influences. These perceptions can deter the construction of new low-income housing or drive existing residents to "flee" the neighborhoods and local schools, causing a downward spiral in the school quality. But are these perceptions real?

The purpose of this paper is to investigate the link between low-income housing, built through the LIHTC program, and neighborhood public school performance. We compile a panel dataset on approximately 4,000 elementary schools in Texas by spatially merging the almost 2,000 LIHTC properties to nearby schools for the 2003-04 through 2008-09 academic years. ${ }^{3}$ The dataset facilitates estimations of the relationship between changes in school academic performance and changes in the numbers of nearby LIHTC units in various contexts. We discuss how the impacts of LIHTC vary when located in neighborhoods with different demographic characteristics and whether the projects are new constructions or rehabilitations. We find little

\footnotetext{
${ }^{3}$ In the remainder of the paper, we will refer to the academic year by its end date. For example, 2003-04 will be 2004.
} 
evidence to suggest negative consequences on local elementary schools from LIHTC units.

Overall, the contemporaneous impacts appear to be positive, statistically significant and robust to various specifications. Offsetting these, the one-year lag effects are negative and of similar or smaller magnitude.

The rest of the paper is organized as follows. In the next section, we provide an overview of the LIHTC program with a focus on the state of Texas. Then, we discuss the mechanisms through which LIHTC units can potentially affect local schools. In the fourth section, we describe the data and main measures of neighborhood and school quality. The fifth section contains the empirical results followed by some discussion and policy implications.

\section{Overview of Low-Income Housing Tax Credit Program}

The LIHTC program was created under the Tax Reform Act of 1986 to incentivize private investors and developers to build rental housing for low-income households. The program gives a dollar-for-dollar federal tax credit to private investors in return for project equity. Investors, such as financial institutions, purchase the tax credits to lower their federal tax liability over a 10-year period. The typical amount of tax-credit-equity raised in a 9 percent taxcredit transaction is between 45 percent and 75 percent of the development costs. ${ }^{4}$ With the tax benefits, the private investors and developers typically need to raise only a fraction of the capital for the projects.

\footnotetext{
${ }^{4}$ Another type of LIHTC offers tax credit at 4 percent. It is not as competitive as the 9 percent credit. Projects financed through tax exempt private investor bond are eligible for the 4 percent credit. Many projects financed with a 4 percent tax credit involve smaller development costs than new constructions, such as rehabilitation and preservation projects.
} 
The rents for LIHTC units that are occupied by qualified low-income households are required to be substantially lower than market rates. To be eligible for the tax credits, either 20 percent of the units must be reserved for households with initial qualifying incomes at or below 50 percent area median income (AMI), or 40 percent of units must go to households with initial qualifying incomes at or below 60 percent AMI. Federal law requires that the rents and incomes remain restricted for 15 years; but some states, such as Texas, apply land-use agreements in order to retain the units in the affordable housing stock for at least 30 years.

The LIHTC is the largest federal rental production subsidy program, producing nearly 2.5 million rental units from 1986 to $2009 .{ }^{5}$ To maximize tax credit dollars, most projects designate all of their units to serve residents with income at or below 60 percent of AMI. LIHTC projects typically have high occupancy rates (95 percent for larger properties and 97 percent for smaller ones) and extremely low foreclosure rates (annualized 0.03 percent between 1991 and 2004, Ernst and Young 2007).

Competition for the tax credits was fierce among developers and states when the economy was growing. The incentives for financial institutions to purchase tax credits reach beyond stable yields and offsetting profits. An investment in a LIHTC state or regional fund can also receive Community Reinvestment Act (CRA) consideration for both a community development loan and a community development investment (Joseph Firschein and Prabal Chakrabarti 2009). ${ }^{6}$ The LIHTC program faced financing challenges starting in 2008,

\footnotetext{
${ }^{5}$ The total drops to nearly 2 million if bond transactions are not included.

${ }^{6}$ The CRA requires federally regulated and insured financial institutions to lend and invest throughout their "assessment areas," where they accept deposits and make a majority of their loans. One of the main principles behind the CRA is that banks and thrifts benefit from the
} 
corresponding with the most recent economic recession. With falling demand for tax credits due to the drop in profits of large investors, the CRA has become the primary incentive for banks to invest in LIHTC projects (JCHS 2009).

In Texas, the Department of Housing and Community Affairs (TDHCA) administers the LIHTC program with some oversight from the state legislature. To date, Texas has allocated approximately $\$ 750$ million in tax credits to developers, leading to an infusion of equity that has contributed to the development of nearly 200,000 affordable housing units.

Figure 1 LIHTC Units and Program Funding in Texas

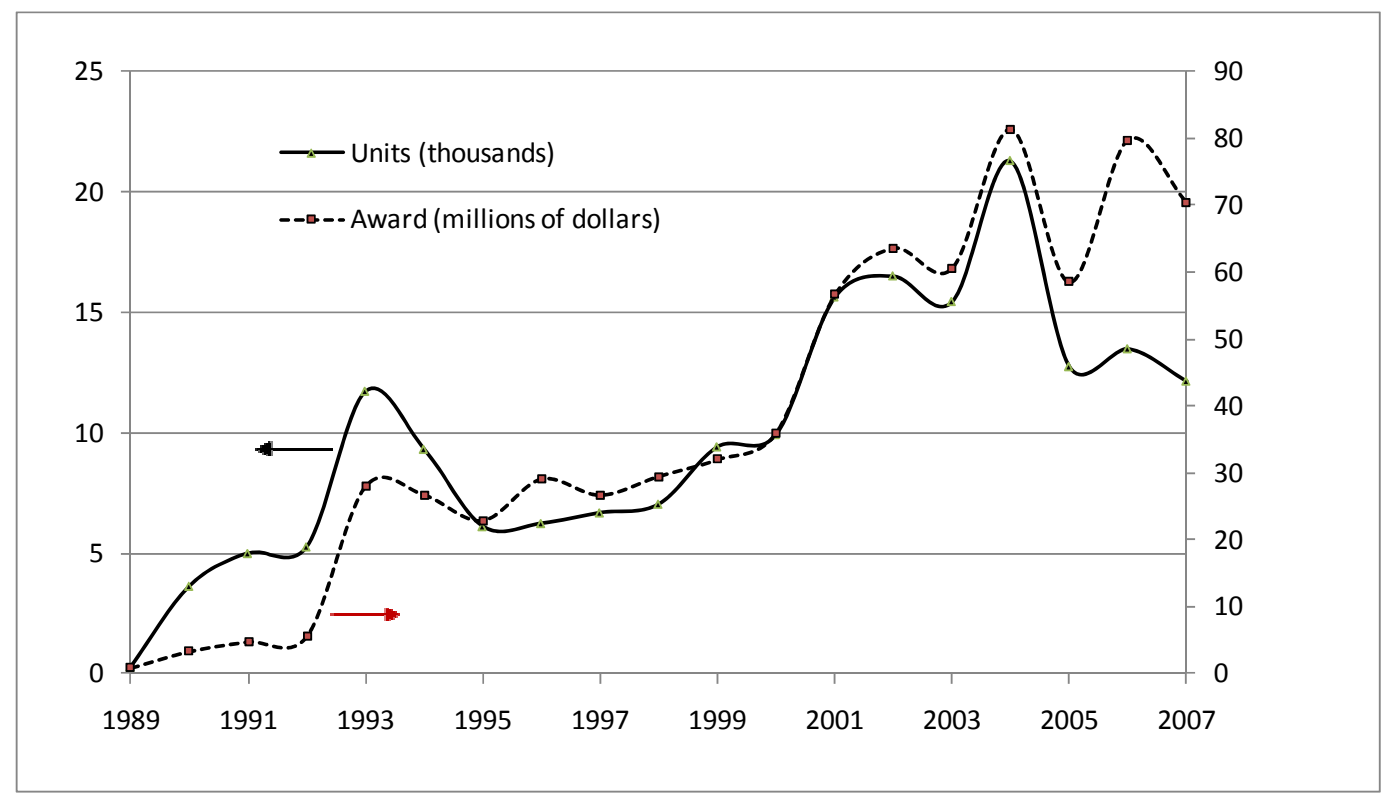

SOURCE: Texas Department of Housing and Community Affairs LIHTC database.

deposits of low- and moderate-income households; in return, they should open access to credit in these communities. The results of the CRA examination are considered when financial institutions apply to open a branch, merge with another institution or become a financial holding company. 
Figure 1 shows the dollar value tax credit awards alongside the total number of units created over the 1989 to 2007 period in Texas. The dashed line (scaled on the right vertical axis) shows a general increase in allocations to Texas LIHTC properties since 1989. The substantial rise is mainly due to the increase in state appropriations by the U.S. Congress in 2001. The solid line (scaled on the left vertical axis) illustrates the number of LIHTC units produced in each year. Note that the units produced are not exactly proportional to tax credit allocation because LIHTC units vary in quality, location and size.

The LIHTC program gives extra tax incentives for properties that are located in "qualified census tracts" - essentially tracts in which 50 percent or more of the households have incomes below 60 percent of the area median gross income, raising concerns about the potential for further concentrating poverty in certain areas. The Texas Legislature addressed this concern by mandating that new LIHTC developments be at least one linear mile from an existing tax credit project or not in a census tract with a large number of existing affordable units. ${ }^{7}$

Previous studies suggest that LIHTC properties deconcentrate low-income renters. Kirk McClure (2006) notes that 43 percent of LIHTC projects are located in suburban census tracts nationally, exceeding the percentage of the housing choice voucher program units in suburbs. Kristopher Rengert (2006) looked at the patterns by state. His results for Texas indicate that the LIHTC properties have relatively high penetration in suburban census tracts; however, the number of LIHTC in lower-poverty census tracts remains relatively low. Roy Lopez and Wenhua Di (2009) examined the distribution of LIHTC properties for Texas counties and found that the LIHTC projects are mostly located in the large metropolitan areas. Large central cities have the

\footnotetext{
${ }^{7}$ The 2010 Housing Tax Credit Program Qualified Allocation Plan and Rules can be found at: http://www.tdhca.state.tx.us/multifamily/htc/docs/10-QAP.pdf
} 
most developments but have not received the largest awards when considered against their population in poverty. While suburban counties do not necessarily have large low-income populations, they are more likely than the central cities to have vacant land available for development. Thus, along with tax incentives, lower projects costs and demand for affordable housing have attracted many developers and investors to the suburban counties. Moreover, not all of the receiving census tracts are lower income. For example, in Tarrant County, more than 40 percent of the LIHTC projects are located in census tracts with median income at or above 80 percent of MSA median income. ${ }^{8}$

\section{Potential Effects of the LIHTC Program on Schools}

There are several ways that LIHTC projects could influence local schools. Even though children in the project may benefit from improved living conditions and family financial situations, if the LIHTC properties are built near schools with limited resources, they may add stress to local schools. If the properties are built around primarily owner-occupied housing, the local schools, especially in the short term, need to be willing and able to foster the integration of poor children, many of whom likely moved from segregated minority neighborhoods. Some studies show that the academic performance of children from low-income households that move to less poor neighborhoods is below the average of their new school (Jacob Vigdor and Jens Ludwig, 2007; Brian Jacob and Jens Ludwig, 2009). Although movers are not necessarily less adaptable to schools than nonmovers (Karl Alexander, Doris Entwisle, and Susan Dauber 1996), being a renter rather than a homeowner is likely to negatively affect kids' academic performance

\footnotetext{
${ }^{8}$ Large metropolitan areas tend to have higher AMI than small rural counties in TX. Therefore, using MSA AMI instead of county AMI for metro counties may lead to a smaller percentage of LIHTC locating in low poverty tracts.
} 
due to the instable environment (Michael Mao, Maria Whitsett, and Lynn Mellor 1997; Eric Hanushek, John Kain, and Steven Rivkin 2004). Therefore, if school demographics change substantially due to LIHTC units, the immediate impact may be to lower the school's overall average on standardized tests and academic rating.

On the other hand, families that have managed to move into a subsidized development in a comparatively wealthy neighborhood are likely to be in better schools with more resources than they were in before. Such changes may facilitate improvements in their children's academic performance. In addition, the parents who move into LIHTC properties in mixed income areas are likely to be relatively motivated, making their children more likely to be relatively high performers. Thomas Boston (2005) found that the families leaving public housing in Atlanta tend to move to mixed income housing or conventional public housing project in superior schools. Such improvements probably reflect a variety of positive influences in the new neighborhoods as well as the characteristics of their families.

The literature is unsettled as to whether or not we should expect the effects on school to linger or change over time. The long-run effect depends on the success of the integration process. The role of peers in modifying achievement is not well understood. Jane Cooley (2006) shows that peer effects mostly take place within reference groups; for example, only peers in the same race and income group would matter. This suggests that importing lower-performing minority kids into a school will not negatively influence the majority. Caroline Hoxby (2000) also finds that students are influenced by their peers and that the effect may be stronger among peers of the same race. Mary Burke and Tim Sass (2008) find nonlinear peer effects. For example, a mean preserving spread in achievement may decrease achievement gains. On the other hand, the lowest achieving students, especially in elementary school, get sizable benefits from middle- and 
high-performing peers. Eric Hanushek et al. (2003) find that the variance does not matter and students throughout the achievement distribution seem to benefit from higher-performing peers. In contrast, William Evans, Wallace Oates, and Robert Schwab (1992) find that peer effects disappear after controlling for simultaneity due to the selection of peers. There is some evidence that kids with different cultural and economic backgrounds improve academic environments. The post-hoc black-white and Hispanic-white achievement gaps appear to be smaller in racially diverse schools, and the SAT score differential between blacks and whites is greater in more racially segregated cities (Valentina Bali and R. Alvarez 2004). Moreover, the neighborhood characteristics seem to matter the most to student academic performance and not the segregation within schools (David Card and Jesse Rothstein 2007).

Other than peer influences, the behavioral responses of parents, teachers, and school administrators also add to the uncertainties of the long-term impacts of LIHTC properties on local schools. While some parents may increase their efforts to compensate for any real or perceived negative impacts, others may simply move out of the LIHTC-receiving areas. If some of the best achieving students leave the local school, the overall performance will suffer. Moreover, the preexisting input combinations in terms of teachers and support staff may be suboptimal after the opening of the LIHTC units. For example, with the arrival of poorer performing students, class sizes may be too large (Edward Lazear 2001). On the other hand, school administrators do seem to respond to accountability ratings (Eric Hanushek and Margaret Raymond 2005); hence, they may try to allocate additional resources and better teachers to mitigate any potential negative impacts. In terms of teacher responses, Amine Ouazad (2008) finds that teachers give higher assessments to children of their own race. Thus, if the LIHTC children enter a situation where most of their teachers are different in terms of race and ethnicity, 
their performance may not improve. Additionally, teachers that are uncomfortable in the new environment may seek alternative locations (Benjamin Scafidia, David Sjoquist, and Todd Stinebrickner 2007).

In light of the literature, how LIHTC projects influence local schools is an empirical question. If students from LIHTC projects are not able to benefit from the new environment or the existing students are adversely affected, then we will observe a negative relationship between LIHTC units and school ratings. Conversely, if the LIHTC units provide a gateway for lowerincome families to access better opportunities for their kids without a detrimental effect on existing schools, and the demographic diversity created by these programs reduces the achievement gaps, then we will observe a positive relationship.

\section{Data}

The data for the empirical analysis come primarily from two sources. The first is the administrative data on LIHTC projects in Texas that is maintained by the Texas Department of Housing and Community Affairs (TDHCA). The dataset contains 2,311 LIHTC properties, including fields such as the property address, purpose (for example, general or limited to elderly residents), date placed in service, number of total units and units reserved for low income tenants, financing information, and the type of project (new construction or rehabilitation). ${ }^{9}$

\footnotetext{
${ }^{9}$ The U.S. Department of Housing and Urban Development (HUD) also maintains a database on LIHTC, but we used its data only for reconciling some addresses or missing values in the TDHCA data. In particular, a key variable we use, the year that the property is placed in service $\left(P I S \_Y E A R\right)$, was constructed with both datasets. Approximately 10 percent of our projects did not have the placed-in-service dates. Rather than deleting the observations, we approximated the placed-in-service year by adding one year to the approval years for the financing from the HUD
} 
These data were address-geocoded - in some cases by calling the property contact person to get the precise location - in order to get the latitudes and longitudes for the properties. After deleting the cases with missing values on the number and type of units or the placed-in-service dates, we ended up with 1,970 observations.

Summary statistics of the TDHCA data are presented in Table 1. Note that the average of low-income units (LOW_UNITS) is approximately 95 percent of the average of all units (UNITS), indicating that the bulk of these projects provide housing exclusively for low-income tenants. Thus, we use UNITS in the remainder of the analysis. In Texas, newly constructed units $(N E W)$ account for about 64 percent of total production of LIHTC units. Table 1 also gives the number of LIHTC projects that were placed in service (PIS_YEAR) from 2003-2008 - the focus years for our analysis. As noted in Figure 1, there were a large number of projects placed in service since the allocation of the tax credit increased in 2001. In our data, approximately 35 percent of the projects were placed in service between 2003 and 2008.

The second primary source of data is the Texas Education Agency (TEA) website, which hosts a multiyear, multitable database on schools in Texas. ${ }^{10}$ Of particular interest, the state accountability system of TEA assigns a rating to every campus and district in the Texas public

data. This algorithm was justified by looking at the relationship between approval dates and placed-in-service dates for the observations with data in both fields.

${ }^{10}$ Campus level data include financial information, teacher information, student characteristics and academic performance. The TEA website also contains a GIS file with the district boundaries and addresses for the campuses within districts. The campus-level data were addressgeocoded in order to get the precise latitudes and longitudes for their locations. See http://www.tea.state.tx.us. 
education system each year. The rating generally falls into one of the four categories: exemplary $(R A T I N G=4)$, recognized $(R A T I N G=3)$, academically acceptable $(R A T I N G=2)$ or academically unacceptable $(R A T I N G=1)$. Ratings and other campus-level data are available from the 1997 to the 2009 academic year. Other rating codes appear in the data such as "not rated," but we did not use any of those observations. Due to the transition of TEA to a new rating system, there were no ratings published for 2003 and starting with 2004 the ratings are based on the new system. Therefore, our analysis focuses on the panel between 2004 and 2009.

In the top portion of Table 2, we present summary statistics for the elementary schools for 2008. Other years produce similar values so we only show one year as an example. For the 2008 school year, the mean of RATING is close to 3 (recognized) and we have data on 4,045 elementary schools. ${ }^{11}$ Only 49 (or 1.2 percent) schools were rated academically unacceptable, 1,059 (or 26.2 percent) schools were rated acceptable, 2,101 (or 51.9 percent) schools were rated recognized, and 836 (or 20.7 percent) schools were rated exemplary. Note that the reason that the number of observations is lower for the change in RATING from the previous year $(\triangle R A T I N G)$ is there were some new schools in 2008. For 2008, 2,342 schools kept the same ratings as the year before, 1,208 schools improved one level, and 317 schools dropped one level in rating. Only 75 schools moved two levels up, and six schools dropped two levels, yielding an overall mean for $\triangle R A T I N G$ of 0.26 .

In terms of the other school and the student characteristics, we see that, in 2008, the majority of the students were minorities (PBLACK and PHISPANIC), almost 62 percent were

\footnotetext{
${ }^{11}$ We only examine schools with appropriate ratings. Besides deleting cases without ratings, we deleted approximately 300 cases with anomalous data in terms of total number of students, total number of teachers and student-teacher ratios.
} 
economically disadvantaged (PLOWSES), and 22.5 percent had limited English proficiency (PLEP). The average elementary school had almost 552 students (NSTUDENTS) and almost 38 teachers for an average student-teacher ratio (STRATIO) of 14.7:1.

Figure 2. Distribution of Changes in TEA Ratings from the Previous Year (19,433 Texas Elementary Schools, 2004-2009)

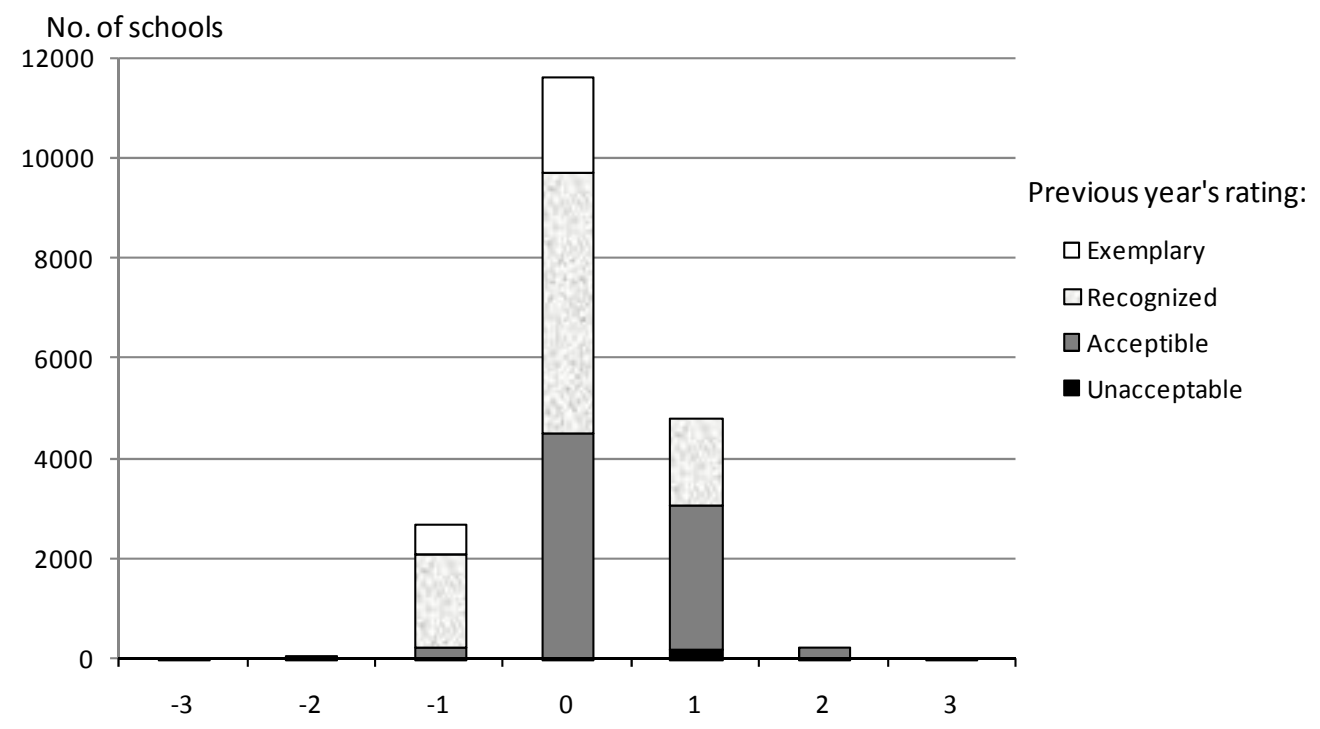

SOURCE: Texas Education Agency Academic Excellence Indicator System

Figure 2 shows the distribution of $\triangle R A T I N G$ for the pooled data. With six years of data, we observe five years of changes for each school for a total number of observations equal to $19,433 .{ }^{12}$ Similar to the 2008 school year, the ratings remain unchanged over one year period for most schools. Some of the schools move up or down one level, but very few move two or more levels. Figure 2 illustrates that most of the schools that improved one level were initially rated academically acceptable. In contrast, those that fell one level were mainly recognized. Among schools rated exemplary, approximately 25 percent fell one level the next year, while only 2 percent fell two levels.

${ }^{12}$ The panel is unbalanced because of some new and closed schools over the study period. 
The TDHCA data on LIHTC properties and the TEA data were merged with a three-step process. First, each LIHTC property was assigned to its school district using a point-in-polygon operation in Geographic Information System (GIS) software. Next, for each year, each LIHTC that existed in that year was assigned to its nearest campus, based on the straight-line distance within the district. ${ }^{13}$ Finally, we determined the total units of LIHTC properties assigned to each school each year. It is important to note that no campuses were assigned a LIHTC property that was outside of its school district even if the property happened to be the closest LIHTC project to the campus. The spatial merge of the data by year facilitates the creation of a school-level panel data with six years of data—2004 to 2009 .

The lower portion of Table 2 shows summary statistics for the LIHTC data spatially merged to the school-level data. By 2008, 374 (or 9 percent) of the 4,045 elementary schools in Texas have at least one LIHTC project assigned to them. For this 9 percent, the average total number of units nearby is 324 although the range is from 1 to 2,761 . Of the 374 projects, 260 and 188 have been classified as either new or rehab project, respectively.

\section{Empirical Analysis}

Using the ratings as an indicator of academic success has its limitations because of small sample sizes per grade level in some elementary schools (Thomas Kane and Douglas Staiger 2002). However, the state accountability system developed by TEA is by far the most comprehensive measure for school performance in Texas. The variables used to determine the ratings include "assessment results on the state standardized assessment instruments as well as longitudinal completion rates and annual dropout rates. Generally, campuses and districts earn

\footnotetext{
${ }^{13}$ For example, LIHTC projects placed in service in 2007 will be considered existing for the 2007-08 academic year.
} 
ratings by having performance that meets absolute standards or by demonstrating sufficient improvement toward the standard" (TEA 2009).

\section{An ordered probit model}

We use the ordered probit model to estimate the direction, magnitude and statistical significance of the impact of nearby LIHTC units on the ratings of elementary schools, which are ordered and take discrete values. Instead of running a fixed-effect ordered probit model on RATING, we calculate the differences in values for all variables and use ordered probit on $\triangle R A T I N G$. This expedites the computing process because the school fixed-effects are differenced out of the model. Additionally, the first-differenced model helps avoid the incidental parameter problem in discrete models with fixed effects (William Greene 2004). In the ordered probit model, the latent variable is estimated as a linear function of the independent variables and a set of cut points. The probability of observing the changes in the accountability rating from the previous year, $\triangle R A T I N G$, corresponds to the probability that the estimated linear function, plus a random error, is within the range of the cut points estimated for the changes in rating:

$$
\operatorname{Pr}\left(\Delta R A T I N G_{j}=i\right)=\operatorname{Pr}\left(C U T_{i-1}<\Delta U N I T S_{j} \beta_{1}+\Delta X_{j} \beta_{2}+T_{j} \beta_{3}+u_{j} \leq C U T_{i}\right)
$$

Where $j$ denotes school, $\Delta U N I T S_{j}$ indicates the changes in LIHTC units from the previous year, $\Delta X_{j}$ are changes in school characteristics or other demographics, $T_{j}$ is a vector of year dummies, which allow the intercepts to differ for each year, and $u_{j}$ is the random error that is assumed to be independent and normally distributed. With six academic years, we have five years of differenced data. As shown in Figure 2 that there are seven values for $\Delta R A T I N G_{j}:-3,-2,-1,0,1$, 2 , and 3 . 
Table 3 shows the coefficient estimates for several specifications. ${ }^{14}$ Model (1) is just $\triangle R A T I N G$ on $\triangle L I H T C$ - a dummy variable that indicates the existence of LIHTC units nearby. The coefficient is positive but not significantly different from zero. The "Cuts" in Table 3 denote the estimated cut points for the underlying latent variable, which we might think of as "academic improvement". In Model (2), we add $\Delta$ UNITS. The coefficient on $\triangle$ UNITS is positive and statistically significant, suggesting that the opening of new LIHTC units is associated with positive changes in the accountability rating of the nearest elementary school. The estimate on $\triangle$ LIHTC is still insignificant. The coefficients on the year dummies are not listed in Table 3, but need to be included in calculating the predicted value of the latent variable. ${ }^{15}$ As suggested in the results of Model (2), a value for the predicted latent variable less than -4.571 will be in the first category of the observed variable $(\triangle R A T I N G=-3)$, while a value greater than 3.303 will be in the highest category $(\triangle R A T I N G=3)$. The ordered probit model also implies a set of marginal effects - the increment to the probability of being in one of the categories from a marginal increase in an independent variable. Once again, using the estimates in Model (2), we find that the increments to the probabilities of being in the seven categories from an additional 100 LIHTC units are: -0.00052 percentage points (to drop three levels), -0.041 percentage points (to drop two levels), -1.36 percentage points (to drop one level), -0.73 percentage points (to stay the same), 1.97 percentage points (to improve one level), 0.16 percentage points (to improve two levels), and 0.0026 percentage points (to improve three levels), respectively. In other words, an

\footnotetext{
${ }^{14}$ To ease the discussion of the results, we drop the $j$ subscript.

${ }^{15}$ For example, in Model (2) the assumed underlying equation is $\hat{y}^{*}=-0.0432 \times \Delta L I H T C+$ $0.000683 \times \Delta U N I T S-0.995 \times Y 2005-0.183 \times Y 2006-0.822 \times Y 2007-0.186 \times$
} $Y 2008$, where $\hat{y}^{*}$ is the predicted value of the latent variable $y^{*}$-academic improvement. 
increase in the number of nearby LIHTC units is associated with an increase of the probability that the nearest school moves upward in its accountability rating or a decrease of the probability that the nearest school moves downward in its accountability rating. ${ }^{16}$ The marginal effects of $\triangle$ UNITS are significant except for the two extreme cases with small sample sizes. ${ }^{17}$

In Model (3), we add the lagged change in the number of LIHTC units, $\triangle$ UNITS $_{-}$, which allows the impact to take longer than one year. The coefficient estimate on $\triangle$ UNITS is now larger, but the lingering effect one year after the new units are placed in service is about the same magnitude but in the opposite direction. ${ }^{18}$ It seems that the initial positive impact from LIHTC units is negated after a year. In Model (4), we control for the change in student-teacher ratio, and its coefficient is negative and statistically significant as expected. Its inclusion does not affect the estimates of the rest of the coefficients. As we control for more campus demographics in Model (5), such as the change in number of students ( $\triangle N S T U D E N T S$ ), the change in the percent of students that are economically disadvantaged ( $\triangle P L O W S E S)$, and the change in the percent white ( $\triangle P$ PHITE), the coefficient estimates on $\triangle$ LIHTC, $\triangle U N I T S$ and $\triangle$ UNITS $_{-I}$ do not change, suggesting a lack of correlation between the LIHTC variables and school demographics. ${ }^{19}$ The

${ }^{16}$ The pattern of these marginal effects does not vary across specifications as long as the means of the other independent variables are used for calculation. So we do not present all of the marginal effects in the paper.

${ }^{17}$ Very few schools improve or drop three levels over one year period as shown in Figure 2.

${ }^{18}$ Multiyear lags are insignificant; therefore, we did not include them in the specification.

${ }^{19}$ None of the simple correlation coefficients between of $\triangle$ UNITS and the changes in the school demographic variables is greater than 0.06. K. Horn and Katherine O'Regan (2010) examined the LIHTC tenant data from TDHCA and also found that the race composition of LIHTC is quite 
coefficient estimates of these variables are of the expected signs and magnitudes, which suggests that the overall structure of the models is valid.

\section{Variation of Impacts by Neighborhood and Project Type}

The effects of LIHTC units on local schools may vary by the initial neighborhood conditions. To investigate this, we divided the neighborhoods according to income and percent minorities in census block groups according to the 2000 Census. Lower (higher) income neighborhood are block groups with median income smaller than or equal to (greater than) 80 percent county median income in 2000; Lower (higher) minority neighborhood are block groups with share of non-Hispanic white smaller than or equal to (greater than) 60 percent in $2000 .^{20}$ There are 150 schools with LIHTC projects in lower income census block groups, and 224 in higher income areas. The average number of total units is 353 in lower-income census block groups, higher than that in higher-income areas (305). There are 136 schools with LIHTC projects in lower-minority census block groups, and 238 in higher-minority areas. The average number of total units is 289 in lower-minority census block groups, lower than that in higherminority areas (344).

Table 4 presents the estimates for census block groups with these four different types of neighborhoods. We only control for the change in the student-teacher ratio in these regressions because we do not expect the inclusion of uncorrelated changes in school demographics to influence the estimated impact of LIHTC units. The estimates of the coefficients of LIHTC

similar to that of the hosting neighborhood. The similarity may also suggest the relatively small number of children living in LIHTC projects comparing to the size of the receiving schools in Texas.

${ }^{20}$ The county median percentage of minority is around 60 percent. 
dummies are still insignificant in all four types of neighborhoods. But for neighborhoods with higher income or lower minority shares, the confidence intervals of the estimates are mostly in the negative region (column three and five in Table 4). This seems to suggest some adverse reaction of schools to the appearance of LIHTC project in those neighborhoods. Turning to the contemporaneous impact of LIHTC units, however, we see significant results only in the block groups with median household income 80 percent or above county median income in 2000 . Moreover, this effect is larger when compared to the entire sample results and it dominates the lagged effect, suggesting an overall positive effect. In higher minority neighborhoods, the impact of the lagged change in units is negative and significant, suggesting an overall negative effect. In lower income and lower minority neighborhoods, LIHTC units do not have a significant impact. Different types of LIHTC projects may bring various neighborhood changes. Therefore, we now consider how LIHTC affect local school outcomes if the projects are rehabilitation or new construction. In Table 5, the first column of coefficients is just Model (4) from Table 3. The next two columns contain the estimates for the new and the rehab projects, respectively. For these regressions, $\triangle$ UNITS is referring to the change in the number of new units for the regression of new projects, and the change in the number of rehab units for the regression of rehab projects. Notice that additional new projects are positively associated with improved academic ratings, while additional rehab units do not affect the ratings. On the other hand, the appearance of a new project in a neighborhood that does not have any other projects $(\triangle L I H T C=$ 1) is not significant but negative and large in magnitude. Considering that higher-income areas are more likely to host new LIHTC units instead of rehabilitated units, this is consistent to our findings in the neighborhood results - some local reaction associated with the construction of new rental units in a neighborhood may negatively affect the school performance, but the 
influence of new students from the project is actually positive. The results for rehabilitation projects represent a very different pattern. None of the policy estimates are significant; hence, given that the rehabilitated units are located in neighborhoods with existing multifamily units, the addition of children from lower-income families does not seem to benefit the local schools.

To explore the relationship a little further, we estimated the model for the various neighborhoods by types of projects. Table 6 displays the signs and significance levels for the coefficient estimates on the new and rehabilitated LIHTC projects in the regressions breaking up the neighborhoods. All of the models include $\triangle S T R A T I O$ and yearly dummies. The coefficient estimates on $\triangle S T R A T I O$ are always negative and significant and not presented. The cut points are also estimated but not presented. For comparison with earlier estimates, we also present the significant signs for the "All units" models that were listed in Table 4 and the first column in Table 5. Overall, the coefficient estimates on $\triangle L I H T C$ are never significant with all the different samples. Evidently, the mere existence of LIHTC units nearby does not influence ratings independently from the effects captured by the number of units. Similarly, we do not see that the "Rehab LIHTC units" generate significant consequences on any neighborhoods. The relationship between LIHTC units and school ratings appears to be driven by the new projects. As noted in Table 5, the contemporaneous influence from the new units is positive, and the influence from the units built a year ago is negative ( 0.00137 versus -0.00108$)$. This same pattern appears in higher-minority areas and in higher-income areas. In the higher-minority areas sample, the estimates are essentially the same magnitude $(0.00120$ versus -0.00117$)$, while in the higherincome sample, the positive influence slightly dominates the negative $(0.0015$ versus -0.0011$)$. The one-year lag of new LIHCT units added has a negative impact on the lower income neighborhood school ratings. 


\section{Influence of LIHTC on state standardized test passing rate}

The opposite directions of the influence of the contemporaneous and the lagged units added imply that the effect new LIHTC units brings students initially helps academic performance, but this effect dissipates over time. It is likely that the new students "converge" toward the school norm after one year. However, as noted above, the rating system is complicated and reflects performance in different socioeconomic, racial and ethnic groups as well as completion and dropout rates, making it difficult to untangle any specific pathway for how LIHTC kids influence the rating. One direct pathway is through the school passing rate of the standardized Texas Assessment of Knowledge and Skills (TAKS) tests—one of the main determinants in the rating scheme. ${ }^{21}$ To analyze this pathway, we constructed a panel of elementary schools with fifth grade TAKS performance (percentage of those taking the tests that meet the passing standard) in the subjects reading (TAKSREAD), mathematics (TAKSMATH) and science (TAKSSCIENCE). Note that the TAKS panel is not the same as the RATINGS panel because some of the elementary schools that we used in the rating models do not have fifth graders. Also, some schools that received ratings may have been granted exemptions for some of the TAKS tests.

Table 7 displays some of the descriptive statistics for the TAKS test variables for $2008 .^{22}$ First we note that the TAKS test passing rates are negatively skewed - the distribution of passing rates tends to cluster after approximately 70 percent passing rates. Also, they tend to be

\footnotetext{
${ }^{21}$ See the Requirements for Each Rating Category at: http://ritter.tea.state.tx.us/perfreport/account/2009/manual/table7.pdf

${ }^{22}$ While the shape of the distributions in 2008 is representative of other years, there is a slight upward trend in average scores over the sample period 2004-2009.
} 
leptokurtic (more peaked) when compared to a normal distribution, which is not surprising given that most schools are rated recognized or exemplary.

We estimate the relationship between TAKS test passing rates and LIHTC units using a first-differenced linear model. The dependent variable is the changes in passing rates for TAKS tests on reading ( $\triangle T A K S R E A)$, math $(\triangle T A K S M A T H)$ or science ( $\triangle T A K S S C I E N C E)$. The independent variables are $\triangle L I H T C, \triangle U N I T S, \triangle$ UNITS $_{-1}, \triangle S T R A T I O$, and annual dummy variables. The results are again insensitive to inclusion of campus-level student demographics once $\triangle S T R A T I O$ is included in the model. Table 7 also shows the relevant summary statistics for the first-differenced TAKS test passing rates in $2008 .^{23}$

The signs of the statistically significant coefficient estimates of the LIHTC variables are presented in Table 8 . The cell is blank if the estimated coefficient is insignificant. The mere appearance of new LIHTC units nearby in an area without existing LIHTC units does not influence the TAKS test passing rates when both types of units are considered. However, the appearance of rehab units has a positive influence in lower-minority areas and a negative influence in lower-income areas on the passing rates of all subjects, and has a negative influence on the TAKS science test passing rate in higher-minority neighborhoods. These results are not

${ }^{23}$ Differencing the data solves the skewness issue, but there appear to be some unusually large changes in passing rates - the interquartile range is generally within plus or minus five points of the means, regardless of the year. Thus, one might suspect that schools with large differences may be influential observations. However, we did not find any reasons for discarding any observations. The residuals were analyzed with leverage and dfbeta diagnostics. See Belsley, Kuh, and Welsch (2004). 
seen in the estimates in the rating models presented in Table 6 as the ratings were calculated based on multiple subjects and other information.

In general, if added LIHTC units have a significant influence, it is positive. The only exception is the influence of rehab units on the passing rate of TAKS reading test in lowerminority area. In addition, if the lagged changes in units have a significant influence, it is always negative and smaller in magnitude than the contemporaneous effect (when both are significant). Overall, the results examining the influence of LIHTC on TAKS tests passing rates are largely consistent with the estimates of the influences on the state accountability ratings.

\section{Discussion}

The LIHTC program has been designed to produce quality workforce housing. However, the addition of multifamily units to the existing housing stock can influence the receiving neighborhoods in various ways. The perceived impact on the academic performance of local public schools remains a main barrier for developing these projects. Higher-income neighbors are worried about inflow of lower-performing students that might exert negative peer influence on their kids or compete for limited resources. There are also concerns that adding more lowincome students to existing struggling schools may exacerbate the isolation in segregated neighborhoods. In this study, we combine the longitudinal school performance data and the LIHTC project administrative data in Texas to investigate the relationship between the development of LIHTC projects and local school outcomes. We use a first-differenced ordered probit model to look at how LIHTC projects affect local public elementary school accountability ratings and a first-differenced linear regression model to examine how LIHTC projects affect the state standardized tests passing rates. 
We find little evidence for overall adverse effects from LIHTC units on neighborhood schools based on the school level analysis. This seems true even though there are no substantial changes in school demographics associated with these projects. In various specifications, the addition of LIHTC units has a positive influence on school accountability rating in the same year as the projects are placed in service. However, the positive influence tapers off after a year-the added units have a negative lingering effect, which is of the same magnitude. As we break down the sample by census demographics, we find that the positive influence is mostly driven by LIHTC units in higher-income census block groups, and the negative influence is largely driven by units in higher-minority or lower-income census block groups. The pattern of influence also differs between different types of LIHTC projects. The addition of new projects seems to increase the likelihood of observing an improvement in the academic performance of the nearest elementary school. Across the various specifications, whenever there is a negative and significant lingering effect, there is an offsetting positive contemporaneous effect. We also find similar results in the estimations of the impact of LIHTC projects on TAKS test passing rates.

It is worth pointing out a couple of data issues we encounter. First, the TDHCA administrative data on LIHTC also record the purpose of the LIHTC projects - either for general or elderly residents. Our analysis was based on the projects for general purpose. We estimated the influence of the changes in LIHTC units designated for the elderly on changes in school accountability ratings and did not find any significant results, suggesting integrity in the independent variables of interest. Second, we attempted to check the accuracy of our method of assigning LIHTC projects to schools. We found approximately 500 schools with sufficient attendance zone information that allows us to compare the nearest school (our approach) to the zoned school. Approximately 75 percent of the zoned schools turned out to be the closest school, 
and many of the rest of the 25 percent were magnet schools. This supports that using the closest school is a reasonable approach given the lack of information on attendance zones over years.

Considering the relatively small inflow of LIHTC children in elementary schools every year in Texas and the lack of correlations of these projects with school demographics, it is surprising to have found any significant relationships at all between LIHTC units and school ratings. However, our results are consistent with the previous literature indicating that such projects are not necessarily detrimental to the receiving neighborhoods. In fact, they seem to support the notion that LIHTC projects allow families of relatively high-performing kids to move to better neighborhoods. The findings of positive influence of LIHTC on higher-income neighborhood schools may dispel some of the concerns of homeowners in the suburban or higher-income areas and help address the barriers of locating LIHTC in these communities. These children living in LIHTC properties may perform better than the existing students at their new schools. This diversification of the receiving neighborhood schools can actually improve campus performance. However, the findings of the negative influence of LIHTC in lowerincome or higher-minority areas again justify the worries that neighborhoods densely populated with low-income residents may limit the advance opportunities for their children. Future studies are needed to specifically disentangle the influence of the various pathways through which housing options translate into educational outcomes. 


\section{References}

Alexander, Karl, Doris Entwisle, and Susan Dauber. 1996. "Children in Motion: School Transfers and Elementary School Performance."Journal of Educational Research, 90(1): 3-12.

Bali, Valentina, and R. Alvarez. 2004. "The Race Gap in Student Achievement Scores: Longitudinal Evidence from a Racially Diverse School District." The Policy Studies Journal, 32(3): 393-415.

Belsley, David, Edwin Kuh, and Roy Welsch. 2004. Regression Diagnostics: IdentifyingInfluential Data and Sources of Collinearity. New York: John Wiley \& Sons.

Boston, Thomas D. 2005. "The Effects of Revitalization on Public Housing Residents: A Case Study of the Atlanta Housing Authority." Journal of the American Planning Association, 71(4), 393-407.

Brunner, Eric, James Murdoch and Mark Thayer. "School Finance Reform and Housing Values." Public Finance \& Management, 2002, 2(4), pp. 535-65

Burke, Mary, and Tim Sass. 2008. "Classroom Peer Effects And Student Achievement." Federal Reserve Bank of Boston Working Paper 1808-5.

Card, David, and Jesse Rothstein. 2007. "Racial Segregation and the Black-White Test Score Gap." Journal of Public Economics, 91(11-12): 2158-84.

Clapp, John, Anupam Nanda, and Stephen Ross. 2008. "Which school attributes matter? The Influence of School District Performance and Demographic Composition on Property Values." Journal of Urban Economics, 63(2): 451-66.

Cooley, Jane. 2010. "Desegregation and the Achievement Gap: Do Diverse Peers Help?" Duke University Working Paper 2010-3.

Deng, Lan. 2009. "Assessing Changes in Neighborhoods Hosting the Low-Income Housing Tax Credit Projects." University of Michigan CLOSUP Working Papers Series 8.

Downs, Anthony. 1992. "Creating more affordable housing." Journal of Housing, 49(4): 17483.

Ellen, Ingrid, Michael Schill, Amy Schwartz, and Ioan Voicu. 2005. "Does Federally Subsidized Rental Housing Depress Neighborhood Property Values?" New York University Law School Law and Economics Research Paper No. 05-04.

Ernst \& Young LLP. 2007. Understanding the Dynamics IV. Housing Tax Credit Performance Report. Retrieved at:

http://www.ey.com/Publication/vwLUAssets/Tax_Understanding_the_dynamicsIV/\$FILE/Tax_ Understanding_the_dynamics_IV.pdf on September 10, 2008.

Evans, William, Wallace Oates, and Robert Schwab. 1992. "Measuring Peer-Group Effects: A Study of Teenage Behavior." Journal of Political Economy, 100(5): 966-91.

Ezzet-Lofstrom, Roxanne, and James Murdoch. 2007. "The Effect of Low-Income Housing Tax Credit Units on Residential Property Values in Dallas County." Williams Review, 1(1): 10724.

Finkel, Meryl, Carissa Climaco, Paul Elwood, Judith Feins, Gretchen Locke, and Susan Popkin. 1996. "Learning from Each Other: New Ideas for Managing the Section 8 Certificate 
and Voucher Program." Paper prepared for the Department of Housing and Urban Development, Washington, D.C.

Firschein, Joseph, and Prabal Chakrabarti. 2009. A Primer on the Low Income Housing Tax Credit (LIHTC) and New Market Tax Credit (NMTC) Programs. A Presentation for Federal Reserve BS\&R. Community Affairs staff and state examination staff. Federal Reserve System.

Greene, William. 2004. "The Behavior of the Maximum Likelihood Estimator of Limited Dependent Variable Models in the Presence of Fixed Effects." Econometrics Journal, Royal Economic Society, 7(1): 98-119.

Hanushek, Eric, John Kain, Jacob Markman, and Steven Rivkin. 2003. "Does Peer Ability Affect Student Achievement?" Journal of Applied Econometrics, 18(5): 527-44.

Hanushek, Eric, John Kain, and Steven Rivkin. 2004. "Disruption Versus Tiebout Improvement: The Costs and Benefits of Switching Schools." Journal of Public Economics, 88(9-10), pp. 1721-46.

Hanushek, Eric, and Margaret Raymond. 2005. "Does School Accountability Lead to Improved Student Performance?" Journal of Policy Analysis and Management, 24(2): 297-327.

Hayes, Kathy, and Lori Taylor. "Neighborhood School Charactersitics: What Signals Quality to Homebuyers?" Federal Reserve Bank of Dallas: Economic Review, 1996, (Fourth Quarter), pp. 1-9.

Horn, K., and Katherine O'Regan. 2010. "The Low Income Housing Tax Credit and Racial Segregation." Paper presented at the 2010 AREUEA Mid-Year Conference.

Hoxby, Caroline. 2000. "Peer Effects in the Classroom: Learning from Gender and Race Variation." NBER Working Paper Series 7867.

Jacob, Brian, and Jens Ludwig. 2009. "Improving Educational Outcomes for Poor Children." Focus, 26(2): 56-61.

Joint Center for Housing Studies (JCHS). 2009. "The Disruption of the Low-Income Housing Tax Credit Program: Causes, Consequences, Responses, and Proposed Correctives." Harvard University.

Kane, Thomas, and Douglas Staiger. 2002. "The Promise and Pitfalls of Using Imprecise School Accountability Measures." Journal of Economic Perspectives 16(4): 91-114.

Lazear, Edward. 2001. "Educational Production." Quarterly Journal of Economics, 116(3): 777-803.

Lopez, Roy, and Wenhua Di. 2009. "Low-Income Housing Tax Credits in Texas: Achievements and Challenges." Banking and Community Perspectives (2).

Mao, Michael, Maria Whitsett, and Lynn Mellor. 1997. "Student Mobility, Academic Performance, and School Accountability." Paper presented at the Annual Meeting of the American Educational Research Association, Chicago, IL.

McClure, Kirk. 2006. The Low-Income Housing Tax Credit Program Goes Mainstream and Moves to the Suburbs. Housing Policy Debate 17(3): 419-46.

Nguyen, Mai. 2005. "Does Affordable Housing Detrimentally Affect Property Values? A Review of the Literature." Journal of Planning Literature 20(1): 15-26. 
Ouazad, Amine. 2008. "Assessed by a Teacher Like Me: Race, Gender, and Subjective Evaluations." INSEAD Working Paper Series 0098.

Pendall, Rolf. 1999. "Opposition to Housing: NIMBY and Beyond." Urban Affairs Review, 35(1): 112-36.

Rengert, Kristopher. 2006. Comment on Kirk McClure's "The Low-Income Housing Tax Credit Program Goes Mainstream and Moves to the Suburbs." Housing Policy Debate 17(3): 473-90.

Santiago, Anna, George Galster, and Peter Tatian. 2001. "Assessing the Property Value Impacts of the Dispersed Housing Subsidy Program in Denver." Journal of Policy Analysis and Management, 20(1): 65-88.

Scafidia, Benjamin, David Sjoquist, and Todd Stinebrickner. 2007. "Race, Poverty, and Teacher Mobility." Economics of Education Review, 26(2): 145-59.

Texas Education Agence (TEA). 2009. "Accountability Manual." http://ritter.tea.state.tx.us/perfreport/account/2009/manual/index.html.

The Reinvestment Fund (TRF). 2009. "Schools in the Neighborhood: Are Housing Prices Affected by School Quality?" Reinvestment Brief, 2009, (6): 1-8.

Turner, Margery, Susan Popkin, and Mary Cunningham. 2000. "Section 8 Mobility And Neighborhood Health." Urban Institute.

Vigdor, Jacob, and Jens Ludwig. 2007. "Segregation and the Black-White Test Score Gap." NBER Working Paper Series no. 12988. 
Table 1. Summary Statistics of the LIHTC Data

\begin{tabular}{llccccc}
\hline Variable & Description & Mean & Std. dev. & Min & Max & No. of obs. \\
\hline UNITS & Number of units & 106.67 & 91.65 & 1 & 826 & 1970 \\
LOW_UNITS & Number of low income units & 101.45 & 88.73 & 1 & 826 & 1970 \\
REHAB & Acquisition/rehabilitation & 0.363 & 0.481 & 0 & 1 & 1970 \\
NEW & New construction & 0.637 & 0.481 & 0 & 1 & 1970 \\
PIS_YEAR & Year placed in service & 1997.7 & 6.85 & 1985 & 2008 & 1970 \\
& PIS_YEAR=2003 & & & & & 113 \\
& PIS_YEAR=2004 & & & & & 105 \\
& PIS_YEAR=2005 & & & & & 145 \\
& PIS_YEAR=2006 & & & & & 135 \\
& PIS_YEAR=2007 & & & & & 97 \\
& PIS_YEAR=2008 & & & & & 89
\end{tabular}

SOURCE: Texas Department of Housing and Community Affairs LIHTC database. 
Table 2. Variable Names, Brief Descriptions and Summary Statistics for the Data on Texas Elementary Schools in 2008

\begin{tabular}{|c|c|c|c|c|c|}
\hline Variable & Description & $\begin{array}{c}\text { No. } \\
\text { of } \\
\text { obs }\end{array}$ & Mean & Min & Max \\
\hline RATING & TEA academic rating & 4045 & 2.9 & 1 & 4 \\
\hline$\triangle R A T I N G$ & Change in TEA rating from 2007 & 3948 & 0.26 & -2 & 2 \\
\hline STRATIO & Ratio of students to teachers & 4045 & 14.7 & 7 & 31.5 \\
\hline NSTUDENTS & Number of students & 4045 & 551.7 & 44 & 1564 \\
\hline PWHITE & $\%$ of students white & 4045 & 35.0 & 0 & 98.4 \\
\hline PBLACK & $\%$ of students black & 4045 & 13.3 & 0 & 100 \\
\hline PHISPANIC & $\%$ of students Hispanic & 4045 & 48.4 & 0 & 100 \\
\hline PLOWSES & $\begin{array}{l}\% \text { of students economically } \\
\text { disadvantaged }\end{array}$ & 4045 & 61.7 & 0 & 100 \\
\hline PLEP & $\begin{array}{l}\% \text { of students with limited English } \\
\text { proficiency }\end{array}$ & 4045 & 22.5 & 0 & 95.1 \\
\hline LIHTC & LIHTC project nearby & 4045 & 0.09 & 0 & 1 \\
\hline UNITS' & Total LIHTC units nearby ${ }^{\prime}$ & 374 & 324.0 & 1 & 2761 \\
\hline$N E W \dagger$ & Total new LIHTC units nearby ${ }^{\dagger}$ & 260 & 224.8 & 1 & 1682 \\
\hline REHAB† & Total rehab LIHTC units nearby ${ }^{\dagger}$ & 188 & 236.4 & 1 & 1684 \\
\hline
\end{tabular}

† Summaries only include nonzero observations 
Table 3. Impact of LIHTC Units on Changes in Elementary School Ratings

\begin{tabular}{|c|c|c|c|c|c|}
\hline Variables & (1) & (2) & (3) & (4) & (5) \\
\hline$\triangle$ LIHTC & $\begin{array}{l}0.0775 \\
(0.125)\end{array}$ & $\begin{array}{r}-0.0432 \\
(0.144)\end{array}$ & $\begin{array}{c}-0.0498 \\
(0.171)\end{array}$ & $\begin{array}{r}-0.0474 \\
(0.171)\end{array}$ & $\begin{array}{r}-0.0294 \\
(0.171)\end{array}$ \\
\hline$\triangle U N I T S$ & & $\begin{array}{l}0.000683^{*} \\
(0.000403)\end{array}$ & $\begin{array}{l}0.000872 * \\
(0.000493)\end{array}$ & $\begin{array}{l}0.000849^{*} \\
(0.000493)\end{array}$ & $\begin{array}{l}0.000838^{*} \\
(0.000494)\end{array}$ \\
\hline$\Delta U N I T S-{ }_{1}$ & & & $\begin{array}{c}-0.000872 * * \\
(0.00038)\end{array}$ & $\begin{array}{c}-0.000851^{* *} \\
(0.00038)\end{array}$ & $\begin{array}{c}-0.000862^{* *} * \\
(0.000381)\end{array}$ \\
\hline$\triangle S T R A T I O$ & & & & $\begin{array}{c}-0.0529 * * * \\
(0.00767)\end{array}$ & $\begin{array}{c}-0.0213^{* *} \\
(0.00858)\end{array}$ \\
\hline$\triangle N S T U D E N T S$ & & & & & $\begin{array}{c}-0.00132^{* * *} * \\
(0.000161)\end{array}$ \\
\hline$\triangle P L O W S E S$ & & & & & $\begin{array}{c}-0.00183 \\
(0.0022)\end{array}$ \\
\hline$\Delta$ WHITE & & & & & $\begin{array}{c}0.0167 * * * \\
-0.00383)\end{array}$ \\
\hline Cuts & $\begin{array}{c}-4.572^{* * *} \\
(0.253) \\
-3.325^{* * *} \\
(0.0463) \\
-1.582^{* * *} \\
(0.021) \\
0.267^{* * *} \\
(0.0184 \\
1.941^{* * *} \\
(0.0287 \\
3.303^{* * *} \\
(0.138)\end{array}$ & $\begin{array}{c}-4.571 * * * \\
(0.253) \\
-3.325^{* * *} \\
(0.0463) \\
-1.582^{* * *} \\
(0.021) \\
0.267 * * * \\
(0.0184) \\
1.942 * * * \\
(0.0287) \\
3.303 * * * \\
(0.138)\end{array}$ & $\begin{array}{c}-4.324 * * * \\
(0.261) \\
-3.293 * * * \\
(0.0601) \\
-1.565 * * * \\
(0.022) \\
0.266 * * * \\
(0.0187) \\
1.947 * * * \\
(0.0296) \\
3.296 * * * \\
(0.138)\end{array}$ & $\begin{array}{c}-4.321 * * * \\
(0.258) \\
-3.300^{* * *} \\
(0.0601) \\
-1.572^{* * *} \\
(0.022) \\
0.262 * * * \\
(0.0187) \\
1.948 * * * \\
(0.0297) \\
3.299^{* * *} \\
(0.138)\end{array}$ & $\begin{array}{c}-4.343^{* * *} \\
(0.258) \\
-3.322^{* * *} \\
(0.0604) \\
-1.587^{* * *} * \\
(0.0223) \\
0.254^{* * *} \\
(0.019) \\
1.948^{* * *} \\
(0.0299) \\
3.305^{* * *} \\
(0.139)\end{array}$ \\
\hline Observations & 19433 & 19433 & 15241 & 15241 & 15241 \\
\hline
\end{tabular}

Standard errors in parenthesis

* significant at 10 percent; $* *$ significant at 5 percent ${ }^{* * *}$ significant at 1 percent 
Table 4. Impact of LIHTC Units on Elementary School Rating in Various Neighborhoods Ordered Probit Regressions.

Dependent Variable $=\triangle R A T I N G$

\begin{tabular}{|c|c|c|c|c|}
\hline Variables & Lower income & Higher income & Higher minority & Lower minority \\
\hline$\triangle L I H T C$ & $\begin{array}{l}0.136 \\
(0.268)\end{array}$ & $\begin{array}{l}-0.195 \\
(0.223)\end{array}$ & $\begin{array}{l}0.0431 \\
(0.202)\end{array}$ & $\begin{array}{l}-0.3 \\
(0.326)\end{array}$ \\
\hline$\Delta U N I T S$ & $\begin{array}{l}0.000231 \\
(0.000727)\end{array}$ & $\begin{array}{l}0.00139 * * \\
(0.000673)\end{array}$ & $\begin{array}{l}0.00055 \\
(0.000584)\end{array}$ & $\begin{array}{l}0.00151 \\
(0.00093)\end{array}$ \\
\hline$\Delta U N I T S_{-1}$ & $\begin{array}{l}-0.000725 \\
(0.000585)\end{array}$ & $\begin{array}{l}-0.000954 * \\
(0.0005)\end{array}$ & $\begin{array}{l}-0.000870 * \\
(0.00045)\end{array}$ & $\begin{array}{l}-0.000765 \\
(0.000717)\end{array}$ \\
\hline$\triangle S T R A T I O$ & $\begin{array}{l}-0.0509 * * * \\
(0.0127)\end{array}$ & $\begin{array}{l}-0.0539 * * * \\
(0.0096)\end{array}$ & $\begin{array}{l}-0.0583 * * * \\
(0.0099)\end{array}$ & $\begin{array}{l}-0.0448 * * * \\
(0.0121)\end{array}$ \\
\hline Cuts & $\begin{array}{l}-3.965 * * * \\
(0.279) \\
-3.270 * * * \\
(0.11) \\
-1.511 * * * \\
(0.0398) \\
0.276^{* * *} \\
(0.0344) \\
2.011 * * * \\
(0.0558) \\
3.187 * * * \\
(0.203)\end{array}$ & $\begin{array}{l}-3.314 * * * \\
(0.0717) \\
-1.600 * * * \\
(0.0264) \\
0.256 * * * \\
(0.0223) \\
1.921 * * * \\
(0.035) \\
3.377 * * * \\
(0.191)\end{array}$ & $\begin{array}{l}-4.137 * * * \\
(0.269) \\
-3.301 * * * \\
(0.0847) \\
-1.572 * * * \\
(0.031) \\
0.258 * * * \\
(0.0263) \\
1.967 * * * \\
(0.0417) \\
3.214 * * * \\
(0.164)\end{array}$ & $\begin{array}{l}-3.304 * * * \\
(0.0853) \\
-1.575 * * * \\
(0.0313) \\
0.265 * * * \\
(0.0266) \\
1.929 * * * \\
(0.0423) \\
3.462 * * * \\
(0.267)\end{array}$ \\
\hline Observations & 4607 & 10634 & 7713 & 7528 \\
\hline
\end{tabular}

Standard errors in parenthesis

* significant at 10 percent; ** significant at 5 percent $* * *$ significant at 1 percent Note:

Lower (higher) income neighborhood: block group median income $\leq(>) 80 \%$ county median income in 2000; lower (higher) minority neighborhood: block group share of non-Hispanic white $\leq(>) 60 \%$ in 2000 . 
Table 5. Impact of New and Rehabilitation LIHTC on Changes in Elementary School Rating 2004-2009 All schools; Ordered Probit Regressions. Dependent Variable $=\triangle$ RATING

\begin{tabular}{|c|c|c|c|}
\hline Variables & All & New projects & Rehab projects \\
\hline \multirow[t]{2}{*}{$\triangle L I H T C$} & -0.0474 & -0.24 & 0.0106 \\
\hline & $(0.171)$ & $(0.18)$ & $(0.268)$ \\
\hline \multirow[t]{2}{*}{$\triangle U N I T S$} & $0.000849 *$ & $0.00137 * *$ & -0.000173 \\
\hline & $(0.000493)$ & $(0.000595)$ & $(0.00101)$ \\
\hline \multirow{2}{*}{$\Delta U N I T S_{-1}$} & $-0.000851 * *$ & $-0.00108 * *$ & 0.000184 \\
\hline & $(0.00038)$ & $(0.000427)$ & $(0.000848)$ \\
\hline \multirow[t]{2}{*}{$\triangle S T R A T I O$} & $-0.0529 * * *$ & $-0.0528 * * *$ & $-0.0531 * * *$ \\
\hline & $(0.00767)$ & $(0.00767)$ & $(0.00766)$ \\
\hline \multirow[t]{12}{*}{ Cuts } & $-4.321 * * *$ & $-4.324 * * *$ & $-4.322 * * *$ \\
\hline & $(0.258)$ & $(0.258)$ & $(0.258)$ \\
\hline & $-3.300 * * *$ & $-3.302 * * *$ & $-3.330 * * *$ \\
\hline & $(0.0601)$ & $(0.0601)$ & $(0.0601)$ \\
\hline & $-1.572 * * *$ & $-1.573 * * *$ & $-1.571 * * *$ \\
\hline & $(0.022)$ & $(0.022)$ & $(0.022)$ \\
\hline & $0.262 * * *$ & $0.261 * * *$ & $0.262 * * *$ \\
\hline & $(0.0187)$ & $(0.0187)$ & $(0.0187)$ \\
\hline & $1.948 * * *$ & $1.947 * * *$ & $1.948 * * *$ \\
\hline & $(0.0297)$ & $(0.0297)$ & $(0.0297)$ \\
\hline & $3.299 * * *$ & $3.299 * * *$ & $3.299 * * *$ \\
\hline & $(0.138)$ & $(0.138)$ & $(0.138)$ \\
\hline Observations & 15241 & 15241 & 15241 \\
\hline
\end{tabular}

Standard errors in parenthesis

* significant at 10 percent; ** significant at 5 percent $* * *$ significant at 1 percent 
Table 6. Signs of the Statistically Significant Estimates of Coefficients on the LIHTC Variables by Type of LIHTC Units and Census Block Group Characteristics in the Ordered Probit Models

Dependent Variables: $\triangle$ RATING

\begin{tabular}{|l|c|c|c|}
\hline Sample & \multicolumn{3}{|c|}{ Explanatory variables } \\
\hline All units & $\Delta$ LIHTC & $\Delta$ UNITS & $\Delta$ UNITS $_{-1}$ \\
\hline All areas & & $+^{*}$ & $-{ }^{* *}$ \\
\hline Lower minority & & & $-*$ \\
\hline Higher minority & & $+^{* *}$ & $-*$ \\
\hline Higher income & & & \\
\hline Lower income & & $+^{* *}$ & $-^{* *}$ \\
\hline New units & & $+^{*}$ & $-^{* *}$ \\
\hline All areas & & $+^{*}$ & $-^{*}$ \\
\hline Lower minority & & & $-*$ \\
\hline Higher minority & & & \\
\hline Higher income & & & \\
\hline Lower income & & & \\
\hline Rehab units & & & \\
\hline All areas & & & \\
\hline Lower minority & & & \\
\hline Higher minority & & & \\
\hline Higher income & & & \\
\hline Lower income & & & \\
\hline
\end{tabular}

* significant at 10 percent; ${ }^{* *}$ significant at 5 percent ${ }^{* * *}$ significant at 1 percent

Significance based on robust standard errors 
Table 7. Summary Statistics for the Elementary Schools with Fifth Grade TAKS Passing Rates in Reading, Mathematics and Science for 2008. $(\mathrm{N}=2,828)$

\begin{tabular}{|l|l|c|c|c|c|c|}
\hline Variable & Description & Mean & Min & Max & Skewness & Kurtosis \\
\hline TAKSREAD & \% Meeting reading standard & 83.6 & 30 & 99 & -0.91 & 3.66 \\
\hline TAKSMATH & \% Meeting reading standard & 84.7 & 27 & 99 & -1.08 & 4.41 \\
\hline TAKSSCIENCE & \% Meeting reading standard & 80.1 & 11 & 99 & -0.92 & 3.90 \\
\hline$\triangle T A K S R E A D$ & $\begin{array}{l}\text { Annual difference in } \\
\text { TAKSREAD }\end{array}$ & 2.93 & -43 & 43 & 0.07 & 5.12 \\
\hline$\triangle T A K S M A T H$ & $\begin{array}{l}\text { Annual difference in } \\
\text { TAKSMATH }\end{array}$ & 0.70 & -45 & 47 & 0.19 & 5.50 \\
\hline$\triangle T A K S S C I E N C E$ & $\begin{array}{l}\text { Annual difference in } \\
\text { TAKSSCIENCE }\end{array}$ & 4.20 & -50 & 66 & 0.38 & 4.96 \\
\hline
\end{tabular}


Table 8. Signs of Statistically Significant Estimates of Coefficient on the LIHTC Variables by Type of LIHTC Project and Census Block Group Characteristics

Dependent Variables: Fifth Grade TAKS Test Passing Rates for Reading (R), Mathematics (M) or Science (S)

\begin{tabular}{|l|c|c|c|c|c|c|c|c|c|}
\hline Sample & \multicolumn{7}{|c|}{ Explanatory variables } \\
\hline All units & \multicolumn{2}{|c|}{$\Delta$ LIHTC } & \multicolumn{3}{|c|}{ UUNITS } & \multicolumn{3}{c|}{ UUNTS -1} \\
\hline All areas & $\mathrm{R}$ & $\mathrm{M}$ & $\mathrm{S}$ & $\mathrm{R}$ & $\mathrm{M}$ & $\mathrm{S}$ & $\mathrm{R}$ & $\mathrm{M}$ & $\mathrm{S}$ \\
\hline Lower minority & & & & $+* *$ & & & & & $-* *$ \\
\hline Higher minority & & & & & & & & & \\
\hline Higher income & & & & $+*$ & & & $-*$ & & $-* *$ \\
\hline Lower income & & & & & & & & & \\
\hline New units & $\mathrm{R}$ & $\mathrm{M}$ & $\mathrm{S}$ & $\mathrm{R}$ & $\mathrm{M}$ & $\mathrm{S}$ & $\mathrm{R}$ & $\mathrm{M}$ & $\mathrm{S}$ \\
\hline All areas & & & & $+*$ & & $+* *$ & $-* *$ & & $-* *$ \\
\hline Lower minority & & & & & & & & & \\
\hline Higher minority & & & $-*$ & $+*$ & & $+* * *$ & $-* * *$ & & $-* * *$ \\
\hline Higher income & & & & $+* *$ & & & & & $-*$ \\
\hline Lower income & & & & & & $+*$ & $-* *$ & & $-* *$ \\
\hline Rehab units & $\mathrm{R}$ & $\mathrm{M}$ & $\mathrm{S}$ & $\mathrm{R}$ & $\mathrm{M}$ & $\mathrm{S}$ & $\mathrm{R}$ & $\mathrm{M}$ & $\mathrm{S}$ \\
\hline All areas & & & & $+* *$ & $+*$ & & & & \\
\hline Lower minority & $+* * *$ & $+* * *$ & $+* * *$ & $-* * *$ & $+* * *$ & $+* *$ & & $-* * *$ & \\
\hline Higher minority & & & & $+*$ & & & & & \\
\hline Higher income & & & & & & & & & \\
\hline Lower income & $-* * *$ & $-* *$ & $-* *$ & $+* * *$ & $+* * *$ & $+* * *$ & & & \\
\hline
\end{tabular}

$*$ significant at 10 percent; $* *$ significant at 5 percent $* * *$ significant at 1 percent Significance based on robust standard errors 